\title{
The seventh edition of the American Joint Committee on Cancer/ International Union Against Cancer Staging Manuals: The new era of data-driven revisions
}

\author{
Valerie W. Rusch, MD, ${ }^{\mathrm{a}}$ Thomas W. Rice, MD ${ }^{\mathrm{b}}$ John Crowley, $\mathrm{PhD},{ }^{\mathrm{c}}$ Eugene H. Blackstone, MD, ${ }^{\mathrm{b}, \mathrm{d}}$ \\ Ramon Rami-Porta, MD, ${ }^{\mathrm{e}}$ and Peter Goldstraw, $\mathrm{MD}^{\mathrm{f}}$
}

Effective January 2010, the seventh editions of the American Joint Commission (AJCC) on Cancer and the International Union Against Cancer (UICC) Staging Manuals were published. ${ }^{1,2}$ These result from intensive collaboration between the UICC and the AJCC and unprecedented efforts to develop and analyze large international databases leading to evidence-based revisions of the staging system. It is important for all thoracic surgeons to be aware of these revisions because they directly affect our daily clinical practice. In the previous and current issues of the Journal, Dr Tom Rice and colleagues present "primers" on the new staging systems for lung and esophageal cancer that explain in straightforward terms the revisions made for the seventh edition of the staging manuals.

The previous revision of the lung cancer staging system occurred in 1997 with the fifth edition of the staging manuals. It was based on analysis of a relatively small single institution (MD Anderson Cancer Center, Houston, TX) database of 5319 cases of non-small cell lung cancers accumulated since 1975. During the past 15 years, reports from other databases increasingly challenged some of the stage descriptors and groupings. The staging systems for small cell lung cancer and carcinoid tumors were also not clearly addressed in the 1997 revision. These deficiencies were highlighted at an International Association for the Study of Lung Cancer (IASLC) workshop held in London in 1996, ${ }^{3}$ prompting the IASLC in 1998 to establish a Lung Cancer Staging Project and Committee, under the leadership of Professor Peter Goldstraw of the Royal Brompton Hospital, London, to bring together large databases available worldwide to form recommendations for the seventh editions of the staging manuals that would be well validated. Cancer Research and Biostatistics (CRAB) in Seattle, Washington, a group with extensive experience managing large clinical trials and databases, agreed to provide biostatistical support

\footnotetext{
From the Thoracic Service, ${ }^{\mathrm{a}}$ Department of Surgery, Memorial Sloan-Kettering Cancer Center, New York, NY; Department of Thoracic and Cardiovascular Surgery, ${ }^{\mathrm{b}}$ Cleveland Clinic, Cleveland, Ohio; Cancer Research and Biostatistics, ${ }^{\mathrm{c}}$ Seattle, Wash; Department of Quantitative Health Sciences, ${ }^{\mathrm{d}}$ Cleveland Clinic, Cleveland, Ohio; Thoracic Surgery Service, ${ }^{\mathrm{e}}$ Hospital Universitari Mutua Terrassa, Terrassa, Spain; and Royal Brompton Hospital, ${ }^{\mathrm{f}}$ Imperial College, London, United Kingdom. Address for reprints: Valerie W. Rusch, MD, Memorial Sloan-Kettering Cancer Center, Thoracic Service, Department of Surgery, 1275 York Avenue, Room C-867, New York, NY 10021 (E-mail: ruschv@mskcc.org).

J Thorac Cardiovasc Surg 2010;139:819-21

0022-5223/\$36.00

Copyright $₫ 2010$ by The American Association for Thoracic Surgery

doi:10.1016/j.jtcvs.2010.02.013
}

for this effort. In conjunction with the IASLC Staging Committee, CRAB developed the data dictionary for submission of data from institutions worldwide. ${ }^{4}$ The database included lung tumor cases diagnosed between 1990 and 2000, a relatively short interval during which staging methods have been constant and which also allowed 5 years of follow-up before analysis. Cases treated by all modalities of care were included. Ultimately, a total of 81,015 analyzable cases from 46 sources in 19 countries were entered into the IASLC database, including 67,725 non-small cell lung cancers, 13,290 small cell lung cancers, and 513 carcinoid tumors. ${ }^{5}$ Analyses led to changes in the T and $\mathrm{M}$ descriptors. Briefly, $\mathrm{T} 1$ and T2 were divided into " $\mathrm{a}$ " and " $\mathrm{b}$ " subcategories to reflect the prognostic impact of tumor size. T2 tumors larger than $7 \mathrm{~cm}$ were reclassified as T3. Separate tumor nodules in the same lobe were reclassified from $\mathrm{T} 4$ to $\mathrm{T} 3$, and those in a separate but ipsilateral lobe from M1 to T4. ${ }^{5,6}$ The M1 category was subdivided into "a" and "b," with M1a including contralateral lung nodules and malignant pleural and pericardial effusions and M1b designating distant metastases. ${ }^{7}$ The $\mathrm{N}$ descriptors remained unchanged, but exploratory analyses suggested that it might be appropriate in future revisions to subdivide the $\mathrm{N} 1$ and $\mathrm{N} 2$ categories into $1 \mathrm{a}, 1 \mathrm{~b}$ and $2 \mathrm{a}, 2 \mathrm{~b}$ on the basis of the number of involved lymph node stations. ${ }^{8}$ Stage groupings also changed to reflect the relationship between the new $\mathrm{T}$ and $\mathrm{M}$ descriptors and overall survival. Subsequent analyses provided external validation of the proposed changes in the staging system through its application to the Surveillance, Epidemiology, and End Results Program database, ${ }^{9}$ defined important prognostic factors, ${ }^{10}$ and showed that the new staging system was also applicable to small cell lung cancer ${ }^{11}$ and carcinoid tumors. ${ }^{12}$ The IASLC recommendations were accepted in full by the UICC and AJCC, and were published in the first organ-specific guidance to the TNM classification in Lung Cancer last year. ${ }^{13,14}$

The esophageal cancer staging system was also revised through an analogous effort, in this case initiated by the AJCC. As for lung cancer, there had been no revisions in the esophageal cancer staging system for the 2 previous editions of the staging manual. A growing body of literature concerning factors associated with survival, including both anatomic and nonanatomic cancer characteristics, suggested that the staging system in the sixth edition of the staging manual no longer accurately categorized tumors. In addition, there was discordance between the esophageal and the 
gastric staging systems, especially with respect to $\mathrm{N}$ staging, which was based on lymph node anatomic location for esophageal tumors and the number of involved lymph nodes for gastric tumors. These differences made it difficult to stage the increasingly common adenocarcinomas of the gastroesophageal junction that theoretically could be classified according to either staging system. Therefore, the AJCC Lung and Esophagus Taskforce spearheaded an initiative to develop a data-driven staging system by forming the Worldwide Esophageal Cancer Collaboration (WECC) under the leadership of Drs Tom Rice and Eugene Blackstone at the Cleveland Clinic. Through the WECC, data were assembled on more than 7000 patients in 13 institutions on 3 continents, 4627 of whom underwent surgery alone for cancers of the esophagus and gastroesophageal junction. In several consensus meetings, analyses of the WECC data were discussed with the AJCC Digestive Cancer Task Force and the UICC to harmonize the esophageal and gastric staging systems and to arrive at final recommendations for revision of the esophageal cancer staging system. Use of a novel statistical methodology, Random Forests, allowed selfvalidation of the analyses. ${ }^{15}$

Key changes in the esophageal cancer staging system include (1) specific definitions of the anatomic boundaries of the cervical, upper, middle, and lower thoracic esophagus and the gastroesophageal junction; (2) recognition of the influence of tumor histology and grade on outcome, especially in early-stage tumors through separate classifications for squamous cell carcinomas and adenocarcinomas; (3) inclusion of gastroesophageal junction tumors into the esophageal staging system, because the survival of these tumors after resection differs from that of more distal gastric cancers; (4) classification of high-grade dysplasia as Tis (in situ carcinoma); (5) subclassification of T4 into " $a$ " and " $b$ "; (6) redefinition of regional nodes as all periesophageal lymph nodes extending from the cervical to the celiac regions; (7) revision of the basis of $\mathrm{N}$ staging from anatomic location to the number of involved lymph nodes $(\mathrm{N} 0=0$, $\mathrm{N} 1=1-2, \mathrm{~N} 2=3-6$, and $\mathrm{N} 3=\geq 7$ lymph nodes involved); (8) elimination of subclassification of $\mathrm{M}$; and (9) extensive revision of the stage groupings.

The pivotal aspect of both of these landmarks efforts is the development of large international databases to allow evidence-based revisions of staging systems with data management and analyses performed by statistical centers experienced in handling large datasets. In addition, although collaboration between the AJCC and the UICC has formally existed since the 1980s, it was more coordinated for the seventh edition of the staging manuals than in the past, thereby eliminating previous discrepancies between the 2 manuals. A similar effort is now under way in malignant pleural mesothelioma under the aegis of the IASLC, CRAB, and the International Mesothelioma Interest Group, and another one may be possible in the future for thymic malignancies. How- ever, the databases for lung and esophageal cancers, although impressive, are imperfect. Both were collected retrospectively and therefore neither totally accurate nor sufficiently granular. The esophageal database was completely based on pathologic staging from patients treated surgically because information on patients treated nonsurgically was not easily accessible and, given the lack of staging examinations required in past trials of chemotherapy and radiation, would not have provided the degree of precision needed for the planned analyses. The data for patients with lung cancer managed surgically were heavily dependent on Japanese sources. Participation by North American surgeons was disappointingly low. To address these issues, data collection, primarily under the direction of the IASLC Staging Committee, is now being undertaken prospectively. ${ }^{16}$ Concerted attempts are being made to obtain both clinical and pathologic staging with truly worldwide representation from patients with both early- and advanced-stage disease. Current staging is still primarily dependent on TNM information. However, especially in lung cancer, rapid advances in molecular medicine during the past 6 years have shown the importance of also classifying tumors on the basis of molecular features. In addition, a recently completed multidisciplinary revision of the histologic classification of lung adenocarcinoma may influence future revisions of the staging system. ${ }^{17}$ Thus, it will be important to consider tumor histologic subtype and molecular data in the analyses of prospectively collected datasets. Broad participation by the international thoracic surgical community is key to the success of these efforts. Groups interested in submitting data on patients with lung cancer or malignant mesothelioma should contact information@crab.org with "IASLC Staging Project" in the subject line. Groups interested in submitting data on patients with esophageal cancer should contact Drs Tom Rice or Gene Blackstone at WECC.

\section{References}

1. American Joint Committee on Cancer. AJCC Cancer Staging Manual. 7th ed. New York: Springer; 2010.

2. International Union Against Cancer. TNM Classification of Malignant Tumours. 7th ed. Oxford, UK: Wiley-Blackwell; 2009.

3. Goldstraw P. Report on the international workshop on intrathoracic staging, London, October 1996. Lung Cancer. 1997;(18):107-11.

4. Goldstraw P, Crowley JJ. The International Association for the Study of Lung Cancer international staging project on lung cancer. J Thorac Oncol. 2006;1:281-6.

5. Goldstraw P, Crowley J, Chansky K, Giroux DJ, Groome PA, Rami-Porta R, et al. The IASLC Lung Cancer Staging Project: proposals for the revision of the TNM stage groupings in the forthcoming (seventh) edition of the TNM classification of malignant tumours. J Thorac Oncol. 2007;2:706-14.

6. Rami-Porta R, Ball D, Crowley J, Giroux DJ, Jett J, Travis WD, et al. The IASLC Lung Cancer Staging Project: proposals for the revision of the T descriptors in the forthcoming (seventh) edition of the TNM classification for lung cancer. J Thorac Oncol. 2007;2:593-602.

7. Postmus PE, Brambilla E, Chansky K, Crowley J, Goldstraw P, Patz EF Jr, et al. The IASLC Lung Cancer Staging Project: proposals for revision of the M descriptors in the forthcoming (seventh) edition of the TNM classification of lung cancer. J Thorac Oncol. 2007; 2:686-93.

8. Rusch VW, Crowley J, Giroux DJ, Goldstraw P, Im J-G, Tsuboi M, et al. The IASLC Lung Cancer Staging Project: proposals for the revision of the $\mathrm{N}$ 
descriptors in the forthcoming seventh edition of the TNM classification for lung cancer. J Thorac Oncol. 2007;2:603-12.

9. Groome PA, Bolejack V, Crowley JJ, Kennedy C, Krasnik M, Sobin LH, et al. The IASLC Lung Cancer Staging Project: validation of the proposals for revision of the T, N, and M descriptors and consequent stage groupings in the forthcoming (seventh) edition of the TNM classification of malignant tumours. J Thorac Oncol. 2007;2:694-705.

10. Sculier J-P, Chansky K, Crowley JJ, van Meerbeeck J, Goldstraw P. The International Association for the Study of Lung Cancer International Staging Committee. The IASLC Lung Cancer Staging Project: the impact of additional prognostic factors on survival and their relationship with the anatomical extent of disease expressed by the 6th edition of the TNM Classification of Malignant Tumours and the proposals for the 7th edition. $J$ Thorac Oncol. 2008;3:457-66.

11. Shepherd FA, Crowley J, Van Houtte P, Postmus PE, Carney D, Chansky K, et al. The IASLC Lung Cancer Staging Project: proposals regarding the clinical staging of small cell lung cancer in the forthcoming (seventh) edition of the TNM classification for lung cancer. J Thorac Oncol. 2007;2:1067-77.
12. Travis WD, Giroux DJ, Chansky K, Crowley J, Asamura H, Jett J, et al. The IASLC Lung Cancer Staging Project: proposals for the inclusion of carcinoid tumors in the forthcoming (seventh) edition of the TNM classification for lung cancer. $J$ Thorac Oncol. 2008;3:1384-90.

13. Goldstraw P. IASLC Staging Handbook in Thoracic Oncology. 1st ed. Orange Park, FL: Editorial Rx Press; 2009.

14. Goldstraw P. IASLC Staging Manual in Thoracic Oncology. 1st ed. Orange Park, FL: Editoral Rx Press; 2009.

15. Rice TW, Rusch VW, Ishwaran H, Blackstone EH. Cancer of the esophagus and esophagogastric junction: data-driven staging for the 7 th edition of the Cancer Staging Manual. Cancer. 2010 (in press).

16. Giroux DJ, Rami-Porta R, Chansky K, Crowley JJ, Groome PA, Postmus PE, et al. The IASLC Lung Cancer Staging Project. Data elements for the prospective project. J Thorac Oncol. 2009;4:679-83.

17. Travis WD, Brambilla E, Noguchi M, Nicholson AG, Geisinger KR, Yatabe Y, et al. IASLC/ATS/ERS international multidisciplinary classification of lung adenocarcinoma. J Thorac Oncol. 2010 (in press). 